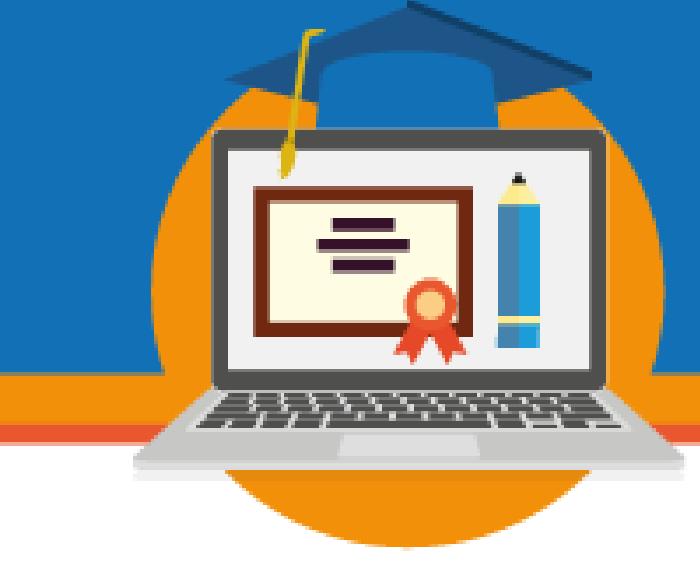

\title{
FORMAÇÃO DOCENTE PARA A EAD
}

Rosselini Diniz Barbosa Ribeiro - IFG/Brasil

(Email: celiniribeiro@gmail.com)

Cláudia Caetano Gonçalves Mendes Lima - IFG/ Brasil

(Email: claudia.caetanogoncalves@gmail.com)

Resumo: Este artigo apresenta um relato de experiência baseado em resultados obtidos em um curso de formação de professores para o uso de tecnologias digitais em função da implantação dos $20 \%$ da carga horária a distância em cursos presenciais. Desde 2010, o Instituto Federal de Goiás (IFG) oferece cursos técnicos de nível médio na modalidade a distância. A partir da Resolução CONSUP/IFG de no $33 / 2017$, ficam estabelecidas as diretrizes para a inclusão de carga horária a distância em cursos presenciais, normatizando a oferta dos $20 \%$. Como inserir a modalidade a distância nas disciplinas presenciais e o que dizem os profissionais sobre esse desafio?

Palavras-chave: Marcos regulatórios da EaD no Brasil; Implantação dos 20\% a distância; Curso de formação docente para a EaD.

Em meio a um processo de expansão da educação superior no Brasil, a Educação a Distância (EaD) surge como modalidade de ensino capaz de oportunizar o acesso para aqueles que não possuem formação em nível superior e, ainda, na maioria das vezes, é chamada a dar respostas aos desafios políticos, sociais, econômicos, pedagógicos e tecnológicos do projeto neoliberal (PRETI, 1998). Esta se constitui em uma de suas críticas, uma vez que as políticas para a $\mathrm{EaD}$ incidem sobre interesses econômicos de certos grupos e, consequentemente, sobre as demandas do mercado, promovendo profundas mudanças nas regulamentações, tendo em vista a flexibilização, diversificação e mercantilização da educação.

Nesse sentido, a Lei de Diretrizes e Bases da Educação (LDB n ${ }^{0}$ 9394/96) se configura como marco regulatório importante para a inserção da $\mathrm{EaD}$ na educação brasileira, visto que estabelece o incentivo ao desenvolvimento e à veiculação de programas de ensino a distância em todos os níveis, modalidades e na formação continuada em seu artigo 80, bem como possibilita a organização de programas de capacitação para todos os professores em 


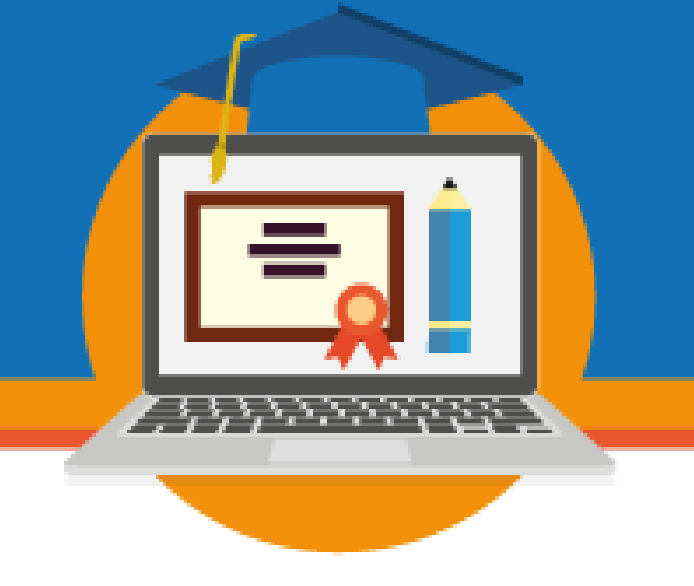

exercício, a partir dos recursos da educação a distância no artigo 87. No entanto, as legislações para a $\mathrm{EaD}$ regulamentam a expansão e o acesso ao ensino superior a partir de uma lógica mercantil, voltada à formação para o trabalho, pautada no aligeiramento formativo e na desresponsabilização do Estado. Os vários decretos, portarias e normatizações que se seguiram compuseram um aparato jurídico regulamentador da EaD no Brasil. A título de breve resgate regulamentatório, destacamos:

- $\quad$ O Decreto $n^{0}$ 2.494, de 10 de fevereiro de 1998, que definiu a Educação a Distância (EaD) como uma forma de ensino que possibilita a autoaprendizagem, com a mediação de recursos didáticos sistematicamente organizados e apresentados em diferentes suportes de organização;

- A Portaria $n^{\circ} 301$, de 7 de abril de 1998, que normatizou os procedimentos de credenciamento de instituições para a oferta de cursos de graduação e educação profissional tecnológica a distância;

- $\quad$ O Decreto $n^{\circ} 2.561$, de 27 de abril de 1998, que altera a redação dos artigos 11 e 12 do Decreto $^{\circ}$ 2.494, de 10 de fevereiro de 1998, delegando ao Ministro de Estado da Educação e do Desporto, a competência para promover o credenciamento das Instituições vinculadas ao sistema federal de ensino e das instituições de educação profisssional tecnológica e de ensino superior dos demais sistemas; e às autoridades integrantes dos demais sistemas de ensino para promover atos de credenciamento de Instituições para oferta de cursos a distância dirigida à educação de jovens e adultos para o ensino médio e educação profissional de nível técnico;

- $\quad$ A Portaria $n^{\circ} 2.253$, de 18 de outubro de 2001, que dispôs sobre a utilização do método não presencial nas instituições de ensino superior do sistema federal de ensino, nas disciplinas de seus cursos superiores;

- A Portaria $\mathrm{n}^{\mathrm{o}} 4.059$, de 10 de dezembro de 2004, que previu a organização curricular e pedagógica dos cursos presenciais com oferta de disciplinas do currículo, utilizando até $20 \%$ da carga horária total do curso na modalidade semipresencial, constando métodos e práticas de ensino e aprendizagem que incorporassem as Tecnologias Digitais da Informação e Comunicação (TDIC), atividades de tutoria e avaliações presenciais; 


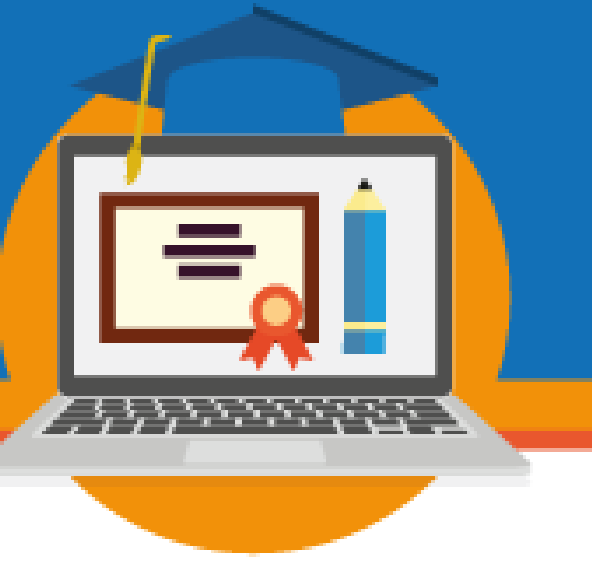

- $\quad$ O Decreto $\mathrm{n}^{\circ} 5.622$, de 19 de dezembro de 2005, que regulamenta o art. 80 da Lei $\mathrm{n}^{\mathrm{o}}$ 9.394, de 20 de dezembro de 1996, que estabelece as diretrizes e bases da educação nacional;

- $\quad$ A Resolução CNE/CEB n 6, de 20 de setembro de 2012, que estendeu a possibilidade de implementação de atividades não presenciais aos cursos técnicos de nível médio presenciais; - A Portaria $n^{0} 1.134$, de 10 de outubro de 2016, que em substituição à portaria anterior, estabeleceu nova redação, reiterando que as instituições que possuem, pelo menos um curso de graduação reconhecido, poderão introduzir na organização pedagógica, disciplinas na modalidade a distância, desde que não ultrapassem os $20 \%$ da carga horária total do curso.

Subjacentes à essas regulamentações está a compreensão de que os processos formativos a distância são mecanismos para suprir déficits educacionais históricos e para garantir expansão e acesso aos diferentes níveis de ensino. No entanto, a educação a distância não pode estar tão somente vinculada ao processo expansionista, ao contrário deve ser comprometida com uma educação emancipatória que promova a apropriação dos saberes construídos historicamente de modo a contribuir para a transformação da realidade. Santos e Nogueira (2017) confirmam o papel das regulamentações dentro desse processo:

\begin{abstract}
No que tange à modalidade a distância, as medidas implementadas pelo ministério, especialmente por meio da legislação para regulação da oferta de EaD no país, embora seja síntese dos embates travados entre os diferentes grupos, apresenta clara influência do mercado e seus atores e está em consonância com as orientações para o ensino superior, provenientes de organizações como a OMC e organismos multilaterais, como o Banco Mundial (SANTOS, NOGUEIRA, 2017, p. 26).
\end{abstract}

É nesse cenário que os Institutos Federais de Educação, Ciência e Tecnologia integram as ações da Rede e-Tec Brasil, ofertando cursos de formação profissional e tecnológica a distância com o objetivo de ampliar, expandir, interiorizar e democratizar a educação em nosso País.

No âmbito do Instituto Federal de Educação, Ciência e Tecnologia de Goiás (IFG), a primeira experiência com a modalidade a distância ocorreu no ano de 2010 com o Curso Técnico Subsequente ao Ensino Médio em Açúcar e Álcool. A partir de 2012, também foram ofertados os Cursos Técnicos em Cerâmica, Edificações e Química e os do Programa 
Profuncionário (Alimentação Escolar, Infraestrutura Escolar, Multimeios Didáticos e Secretaria Escolar), direcionados para a formação dos profissionais da educação não docentes das redes municipal e estadual de ensino, em nível subsequente ao Ensino Médio.

Ao longo desses anos de implantação da modalidade a distância no IFG, a Diretoria de Educação a Distância (DEaD) dialogou com o Colégio de Dirigentes, Conselho de Ensino, Pesquisa e Extensão (CONEPEX), Conselho Superior (CONSUP), através da Câmara de Ensino, com os Departamentos de Áreas Acadêmicas dos Câmpus, com a comunidade interna em geral (consultas públicas e colóquios), e com outras instâncias setoriais (Pró-Reitorias) para a implementação de políticas de educação a distância visando a institucionalização da modalidade. Em 02 de outubro de 2017, a Resolução CONSUP/IFG de $n^{0} 33$ aprovou as diretrizes operacionais para a inclusão de carga horária na modalidade a distância em cursos presenciais, estabelecendo normas procedimentais para o planejamento da oferta dos $20 \%$ da carga horária a distância, nos cursos técnicos de nível médio e de graduação presenciais.

Nesse contexto, a Diretoria de Educação a Distância (DEaD) identificou a necessidade de promover um curso de formação sobre o uso crítico de tecnologias digitais da informação e comunicação (TDIC), visando o desenvolvimento de competências em âmbito técnico-pedagógico para a oferta de disciplinas a distância. Em dezembro de 2017, iniciou-se a primeira turma, composta por docentes e técnicos administrativos da própria Instituição.

A seguir, apresentamos o formato do curso e, a partir da análise de dados dos questionários e das participações dos cursistas no decorrer do Módulo I, propomos uma reflexão sobre os desafios e as possibilidades desse tipo de formação para o aprimoramento das práticas pedagógicas no contexto da cultura digital e da EaD.

\section{O CURSO DE FORMAÇÃO DE PROFESSORES PARA A DOCÊNCIA ONLINE}

É comum pensar que as Tecnologias Digitais da Informação e Comunicação (TDIC) já estão incorporadas ao ambiente escolar, uma vez que estas fazem parte da nossa cultura e se fazem presentes no cotidiano das pessoas. Para Belloni (2012, p. 114), por exemplo, 


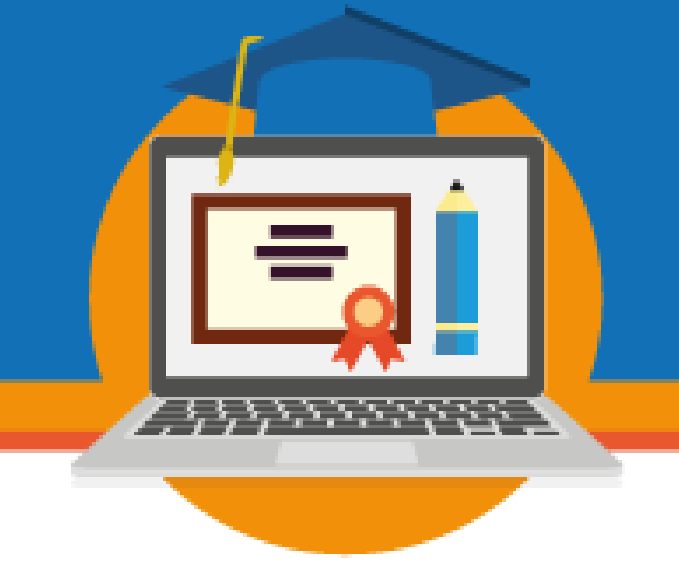

não é mais uma questão de opção, “as tecnologias já estão no mundo, transformando todas as dimensões da vida social e econômica; cabe ao campo educacional integrá-las e tirar de suas potencialidades comunicacionais e pedagógicas o melhor proveito". Todavia, destacamos que, mesmo sendo nativos digitais, é fundamental que os professores possuam formação técnica e pedagógica para o uso efetivo das tecnologias da informação e comunicação nas práticas educacionais.

Além disso, quando se trata dos processos formativos online não se pode perder de vista a semelhança entre a educação presencial e a educação a distância, isto é, os saberes pedagógicos que se fazem presentes em ambas as modalidades e visam a aprendizagem, a formação humana e o desenvolvimento da autonomia intelectual, a partir de um compromisso com uma educação emancipatória que promova a transformação da vida das pessoas (TOSCHI, 2004).

Desse modo, o "Curso de formação para o uso de tecnologias digitais da informação e comunicação em disciplinas presenciais e a distância" tem o objetivo de oferecer formação técnica e pedagógica para o uso de tecnologias digitais de informação e comunicação em disciplinas presenciais e a distância, em conformidade com as concepções e objetivos educacionais do IFG, quais sejam: "[...] mediar, ampliar e aprofundar a formação integral (omnilateral) de profissionais-cidadãos, capacitados a atuar e intervir no mundo do trabalho, na perspectiva da consolidação de uma sociedade democrática e justa social e economicamente" (PDI/IFG, 2012-2016, p. 10).

A previsão da carga horária do curso é de $75 \%$ a distância, com a realização de atividades no Moodle e por webconferências agendadas, e $25 \%$ presencial em dois dias de encontro no Laboratório de Informática da $\mathrm{DEaD}$. A previsão é de $12 \mathrm{~h}$ semanais de estudos, a partir da leitura de textos, de videoaulas e da realização de atividades formativas diversas, como: fórum com questionamentos disparados pelo docente, fórum de dúvidas aberto todo o tempo durante a vigência da disciplina, questionários, autoavaliações e avaliações dos processos pedagógicos de cada disciplina, dentre outras. 


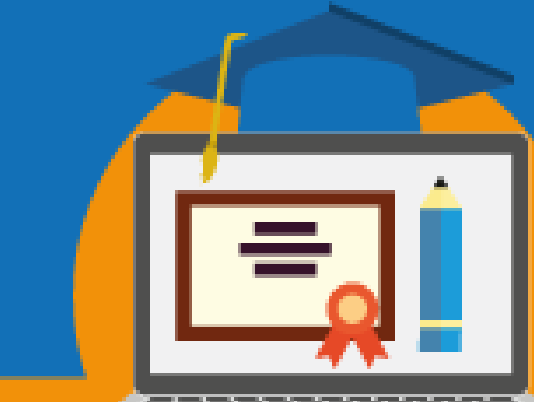

O curso está dividido em dois módulos. O Módulo I compreende as disciplinas Ambiente Virtual de Ensino e Aprendizagem (AVEA) - Moodle, Fundamentos da EaD e Docência Online; o Módulo II contempla as disciplinas Fundamentos da Educação Especial na Perspectiva Inclusiva, Uso Pedagógico de Ferramentas Digitais, Produção de Material Didático Digital e Produção de Material Audiovisual.

Na segunda oferta, há a previsão de $20 \%$ das vagas para a comunidade externa e a terceira oferta será oferecida tanto para a comunidade interna quanto externa dentro do número de vagas.

\section{O QUE OS DADOS REVELAM?}

A partir do questionário de apresentação do estudante, aplicado à primeira turma do "Curso de formação para o uso de tecnologias digitais da informação e comunicação em disciplinas presenciais e a distância", foram coletadas informações relacionadas à $\mathrm{EaD}$ e ao uso das tecnologias. A pesquisa contou com a participação de 29 cursistas, selecionados por meio do aceite do termo de autorização de pesquisa. Para a análise dos dados, apresentamos a seguir algumas das questões formuladas e os resultados encontrados:

\section{Titulação:}

\section{Gráfico 1: Titulação}




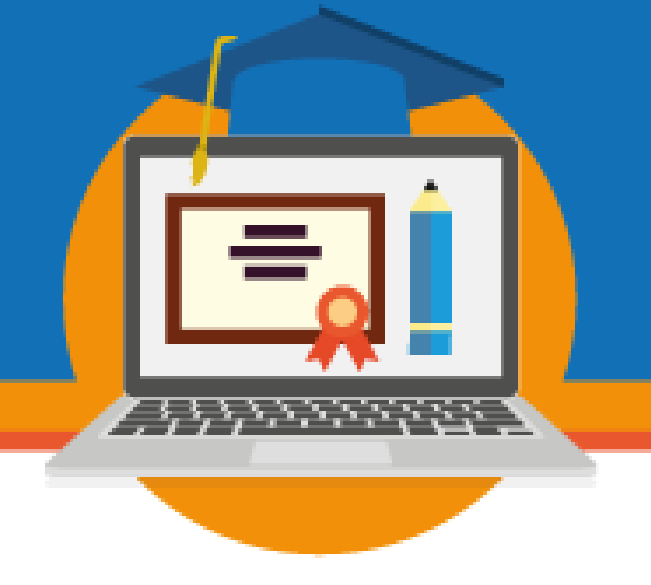

Dos vinte e quatro (24) cursistas que declararam ter participado de cursos a distância, 75\%, isto é, dezoito (18) estudantes destacaram que pelo menos um dos seus processos formativos em EaD ocorreu em instituições públicas de ensino (IFG, UFG, UFMS, UFU, UnB, UEG, ENAP).

\section{Caso tenha participado de algum curso a distância, em que papel atuou?}

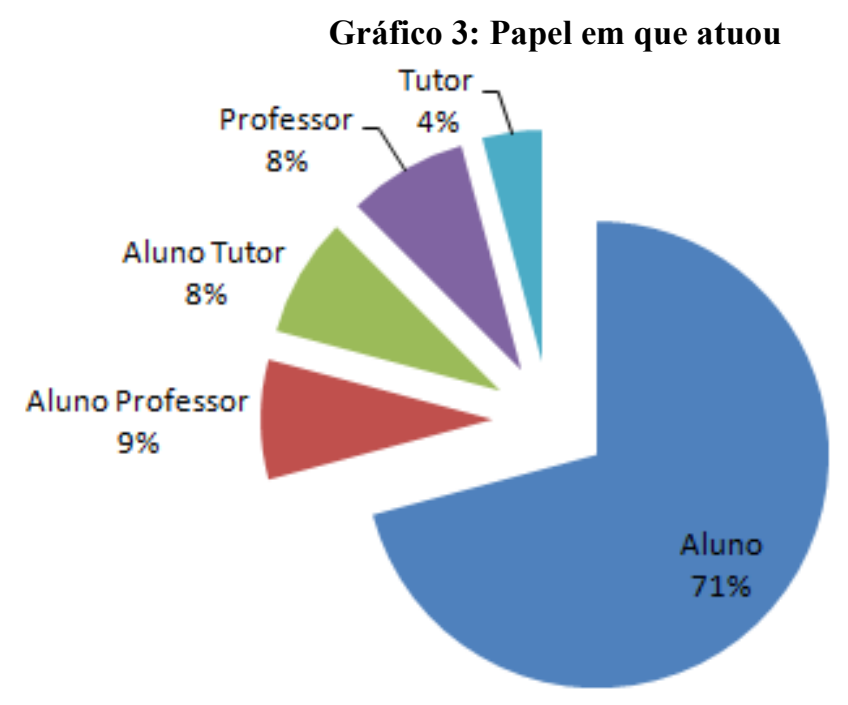

Fonte: Elaborado pelas autoras (2018)

Como explicitado no gráfico, apenas dois (2) cursistas possuíam experiência em docência online.

\section{Qual motivo o levou a se inscrever no curso?}

Para responder a essa questão foram dadas as alternativas abaixo, podendo ser escolhida mais de uma opção:

- $\quad 86,21 \%$ afirmam que espera agregar conhecimento ao trabalho que desenvolvem;

\section{SEMINÁRIO DE EDUCAÇÃO A DISTÂNCIA}

EaD na região Centro-Oeste: Institucionalização, Limites e Potencialidades

12 a 14 de abril de 2018 - Campo Grande/MS 


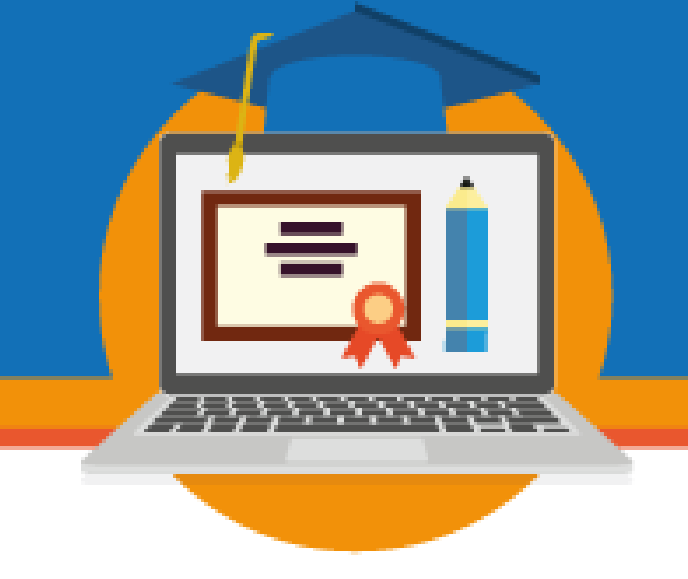

- $65,52 \%$ querem ministrar atividades não presenciais em função da implantação de $20 \%$ a distância em cursos presenciais;

- $\quad 24,14 \%$ não têm tempo para frequentar diariamente um curso presencial;

- $6,9 \%$ têm necessidade de carga horária para alcançar pontuação ou progressão funcional;

- $\quad 3,45 \%$ acham que um curso a distância é mais fácil do que um curso presencial.

\section{Se docente, em caso de implantação de $20 \%$ da disciplina a distância em curso presencial, tem interesse em oferecer alguma disciplina?}

Todos os docentes que participaram da pesquisa afirmaram ter interesse em ofertar alguma disciplina a distância. 29,41\% declararam que pretendem implementar os $20 \%$ da carga horária a distância nas disciplinas que já ministram.

\section{Em relação ao uso das tecnologias, marque as ferramentas utilizadas:}

- $\quad 96,55 \%$ utilizam e-mail;

- $\quad 86,21 \%$ whatsapp;

- $\quad 82,76 \%$ pacote Office (Word, Excel, PowerPoint)

- $\quad 68,97 \%$ aplicativos do celular;

- $\quad 65,52 \%$ Google docs, planilhas ou slides online;

- $\quad 55,17 \%$ ferramentas de interação audiovisual (Hangouts, Youtube, Skype, outros);

- $41,38 \%$ ferramentas online para pesquisa como por exemplo, Google forms, LimeSurvey, etc.;

- $\quad 31,03 \%$ ferramentas de criação de vídeos, animações, videoaulas, outros;

- $\quad 24,14 \%$ ferramentas de criação de produção autoral de sites e blogs;

- $\quad 20,69 \%$ ferramentas online para criação de nuvem de palavras;

- $17,24 \%$ ferramentas online para criação de mapa conceitual; 


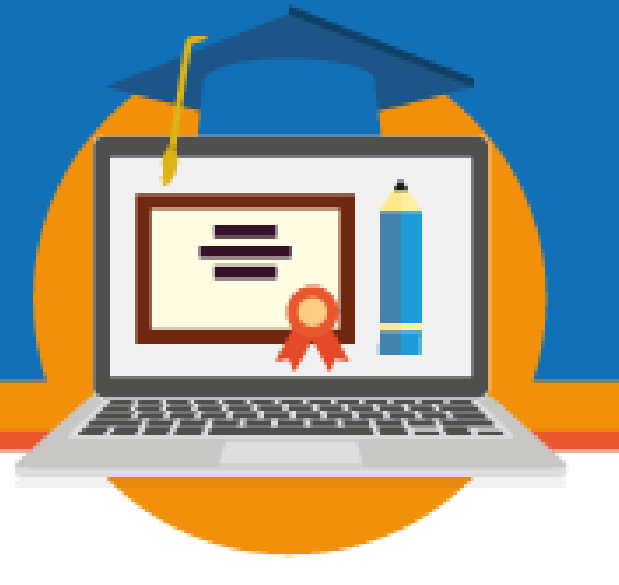

- $\quad 13,8 \%$ ferramentas online de criação de infográficos ou panfletos.

Essa questão também permitia a marcação de mais de uma alternativa. Os dados apresentados revelam que as ferramentas mais utilizadas pelos cursistas são aquelas de suas demandas cotidianas, como e-mail, whatsapp e pacote office. Poucos utilizam as ferramentas digitais para o desenvolvimento do processo de ensino e aprendizagem, como as de criação de nuvem de palavras, mapa conceitual, vídeos, animações, videoaulas, dentre outras.

7. Você identifica dificuldades ao usar a tecnologia em seu ambiente de trabalho?

Gráfico 4: Identifica dificuldades ao usar a tecnologia no ambiente de trabalho

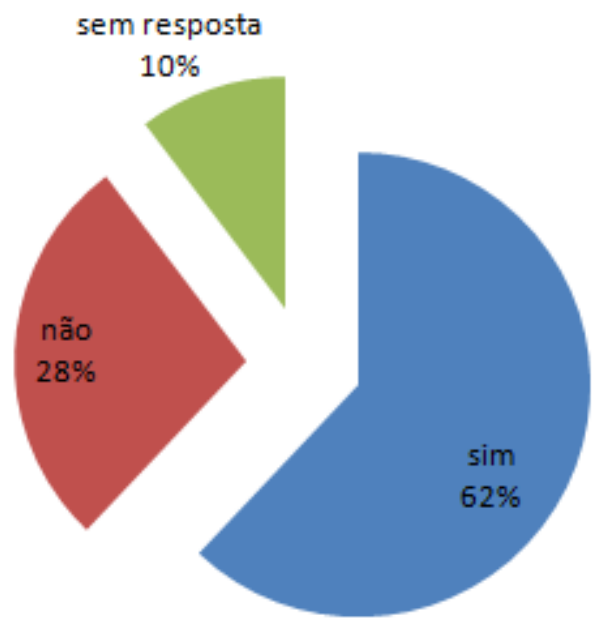

Fonte: Elaborado pelas autoras (2018) 


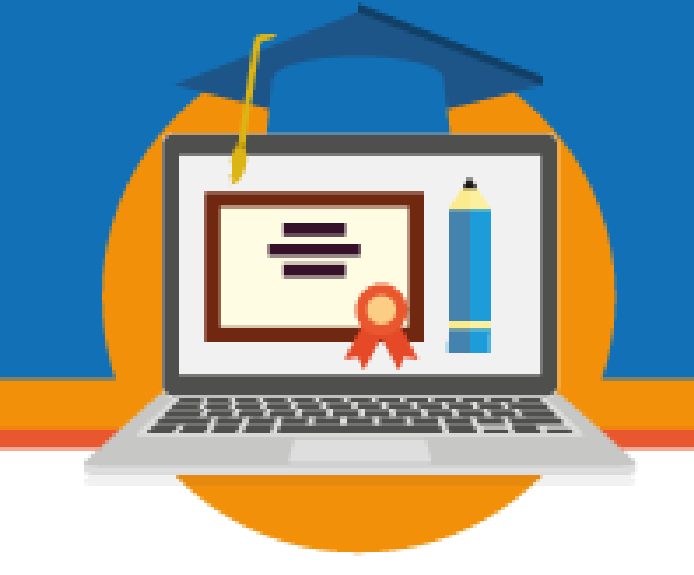

A falta de suporte técnico, acesso satisfatório à internet, qualificação para o uso das TDIC e estrutura física (laboratório de informática e local para gravação de videoaula) são as dificuldades mais apontadas pelos participantes.

\section{Quais as suas expectativas em relação ao curso?}

Apenas um participante não relatou suas expectativas em relação ao curso. De maneira resumida, as expectativas foram:

- Aprender a explorar mais as ferramentas digitais e compreender como se dá o processo de ensino e aprendizagem através da modalidade a distância;

- Aprender novas formas para desempenhar a função docente e para estar mais próximo dos alunos;

- Aprender a ser mais criativo no preparo das aulas e mais disponível na interação com os estudantes;

- Melhorar a prática docente a partir das TDIC, tornando as aulas mais interessantes e atrativas com novas metodologias em $\mathrm{EaD}$;

- Aprender a utilizar os recursos disponíveis para otimizar o Ambiente Virtual de Ensino e Aprendizagem (AVEA);

- $\quad$ Aprender mais sobre Educação a Distância;

- Agregar conhecimento e conhecer mais sobre as tecnologias digitais para contribuir para o trabalho e estudo;

- Superar dificuldades em lidar com a tecnologia.

$\bullet$

\section{CONSIDERAÇÕES FINAIS}

Frente à regulamentação da implantação de carga horária de $20 \%$ a distância em cursos presencias do IFG, prevista na Resolução CONSUP/IFG de ${ }^{0}$ 33, de 2 de outubro de 2017, é preciso pensar em ações que contribuam para a implementação da modalidade a distância com processos formativos que garantam a qualidade do ensino e uma formação comprometida com a sistematização e difusão do conhecimento científico, tecnológico, filosófico, artístico e cultural (PDI/IFG, 2012-2016, p. 10), promotora do pleno desenvolvimento dos educandos. 


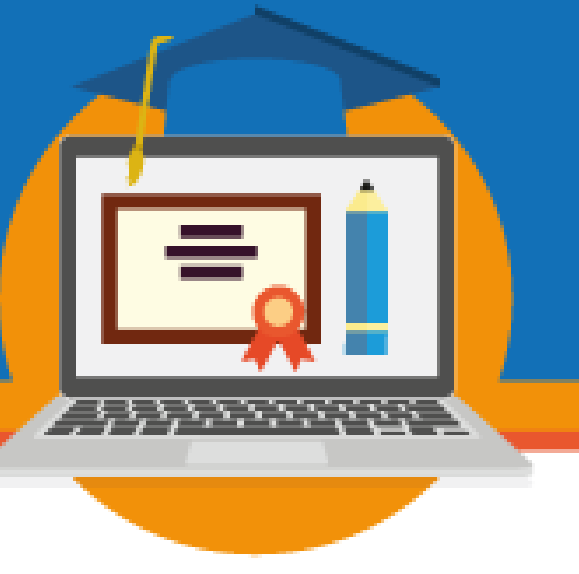

Nesse sentido, é necessário repensar práticas pedagógicas, compreendendo as particularidades do ensino a distância, sem perder de vista os objetivos educacionais que devem nortear as ações de ensino e aprendizagem, sejam elas desenvolvidas de forma presencial ou a distância.

Os resultados apresentados pela pesquisa apontam a necessidade de um planejamento quanto às questões técnicas, como por exemplo, profissionais de suporte de TI e audiovisual em cada Câmpus e acesso à internet que garanta transmissões online com boa qualidade e contemple muitos acessos simultâneos, bem como o planejamento para a implementação pedagógica, assegurando formação para a utilização das TDIC de modo a garantir o alcance dos objetivos educacionais de cada disciplina.

No que se refere ao aspecto pedagógico, o formato proposto pelo curso de formação (75\% a distância) oportunizará aos participantes a vivência de situações concretas como alunos no Ambiente Virtual de Ensino e Aprendizagem, reconhecendo a importância das interações, sejam elas síncronas - quando estão em aula no mesmo momento, por exemplo em um chat e assíncronas - quando realizam as atividades em momentos diferentes.

O discurso de que as tecnologias já fazem parte do cotidiano e, por essa razão, devem ser inseridas no contexto escolar limita a questão à uma perspectiva determinista que pressupõe a transferência automática das potencialidades técnicas dos meios comunicacionais às práticas pedagógicas (ARAÚJO; PEIXOTO, 2016). Em contraponto à essa visão, pode-se observar o interesse dos cursistas em aprender a lidar com esses recursos, evidenciando a necessidade de ampliação do conhecimento das suas possibilidades para o desenvolvimento da aprendizagem dos estudantes. Assim, o "Curso de formação para o uso de tecnologias digitais da informação e comunicação em disciplinas presenciais e a distância" objetiva a articulação entre os aspectos teóricos e práticos voltados para a apropriação crítica das tecnologias. Cabe ressaltar que implantar os $20 \%$ sem uma formação abrangente que envolva os fundamentos teórico-metodológicos da mediação pedagógica é incorrer no risco de reproduzir velhas práticas com o uso de tecnologias, adotando concepções instrumentais e tecnicistas no ensino, esquecendo-se de que as tecnologias, por si só, não garantem a aprendizagem. 


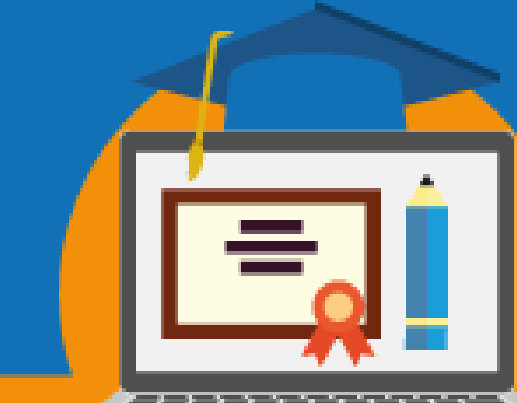

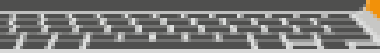

\section{REFERÊNCIAS}

ARAÚJO, C. H. S.; PEIXOTO, J. Docência online: trabalho pedagógico mediado por tecnologias digitais em rede. ETD. Educação Temática Digital. v. 18. p. 404-417, 2016.

BELLONI, M. L. Educação a distância. 6. ed. Campinas: Autores Associados, 2012.

BRASIL. Decreto $n^{\circ} 2.494$, de 10 de fevereiro de 1998. Regulamenta o art. 80 da Lei $n^{\circ} 9.394$, de 20 de dezembro de 1996, e dá outras providências. Diário Oficial da República Federativa do Brasil, Brasília, DF, 10 fev. 1998. Disponível em: <http:// www. 2.camara.leg.br/legin/fed/decret/1998/decreto-2494-10-fevereiro-1998-397980-publicacao original-1-pe.html>. Acesso em 18 fev. 2018.

BRASIL. Decreto $n^{\circ} 2.561$, de 27 de abril de 1998. Altera a redação dos arts. 11 e 12 do Decreto $\mathrm{n}^{\circ}$ 2.494, de 10 de fevereiro de 1998 que regulamenta o disposto no art. 80 da Lei $\mathrm{n}^{\circ}$ 9.394/96. Diário Oficial da República Federativa do Brasil, Brasília, DF, 27 abril 1998. Disponível em: <http://portal.mec.gov.br/seed/arquivos/pdf/tvescola/leis/D2561.pdf>. Acesso em 10 dez. 2017.

BRASIL. Decreto $n^{\circ}$ 5.622, de 19 de dezembro de 2005. Regulamenta o art. 80 da Lei $n^{\circ}$ 9.394, de 20 de dezembro de 1996, que estabelece as diretrizes e bases da educação nacional. Diário Oficial da República Federativa do Brasil, Brasília, DF, 19 dez. 2005.Disponível em: $<$ http://www.planalto.gov.br/ccivil_03/_ato2004-2006/2005/decreto/d5622.htm>. Acesso 


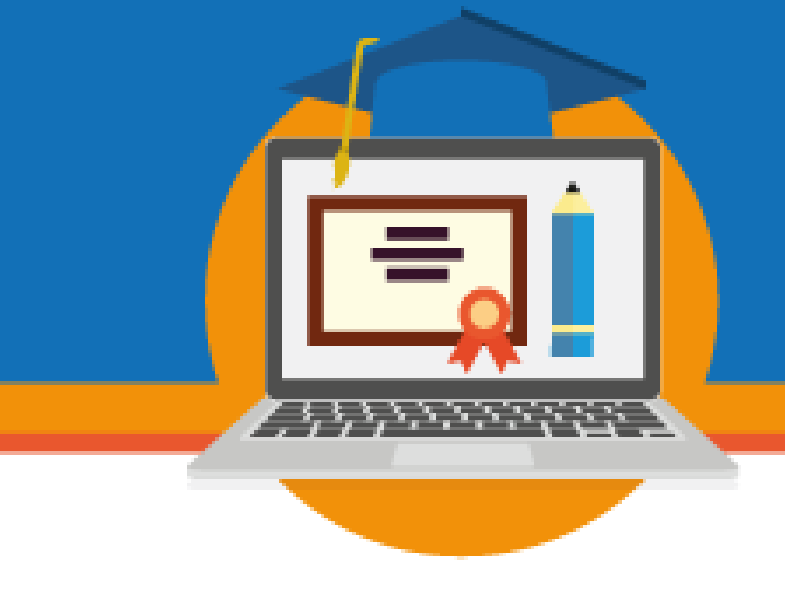

em 10 dez. 2017.

BRASIL. MEC. LDB - Lei n⿳0 9394/96. Estabelece as diretrizes e bases da Educação Nacional. Brasília: MEC, 1996. Disponível em: <http://portal.mec.gov.br/seesp/arquivos/pdf/ lei9394 1dbn1.pdf>. Acesso em: 10 dez. 2017.

BRASIL. Portaria $\mathrm{n}^{\mathrm{o}}$ 301, de 7 de abril de 1998. Normatiza os procedimentos de credenciamento de instituições para a oferta de cursos de graduação e educação profissional tecnológica a distância. Diário Oficial da República Federativa do Brasil, Brasília, DF, 7 abr. 1998. Disponível em: <http://portal.mec.gov.br/seed/arquivos/pdf/tvescola/leis/port301. pdf $>$. Acesso em: 20 jan. 2018.

BRASIL. Portaria $n^{0}$ 2.253, de 18 de outubro de 2001. Dispõe sobre a introdução nas instituições de ensino superior do sistema federal de ensino, na organização pedagógica e curricular de seus cursos superiores reconhecidos, a oferta de disciplinas que, em seu todo ou em parte, utilizem método não presencial, com base no art. 81 da Lei n. 9394, de 1996. Diário Oficial da República Federativa do Brasil, Brasília, DF, 18 out. 2001. Disponível em: $<$ http://www2.camara.leg.br/legin/marg/portar/2001/portaria-2253-18-outubro -2001-412758-publicacaooriginal-1-me.html>. Acesso em: 12 dez. 2017.

BRASIL. Portaria $n^{\circ}$ 4.059, de 10 de dezembro de 2004. Prevê a organização curricular e pedagógica dos cursos presenciais com oferta de disciplinas do currículo, utilizando até $20 \%$ da carga horária total do curso na modalidade semipresencial e o uso de métodos e práticas de ensino e aprendizagem que incorporassem as Tecnologias Digitais da Informação e Comunicação para a realização dos objetivos pedagógicos. Diário Oficial da República Federativa do Brasil, Brasília, DF, 10 dez. 2004. Disponível em: <http://portal.mec. gov.br/sesu/arquivos/pdf/nova/acs_portaria4059.pdf> Acesso em: 22 fev. 2018.

BRASIL. Portaria $\mathrm{n}^{\circ} 1.134$, de 10 de outubro de 2016 . Revoga a portaria $\mathrm{n}^{\circ} 4.059$, de dezembro de 2004 e estabelece nova redação para o tema. Diário Oficial da República Federativa do Brasil, Brasília, DF, 10 out. 2016. Disponível em: <https://abmes.org. br/arquivos/legislacoes/Port-MEC-1134-2016-10-10.pdf>. Acesso em: 10 dez. 2017.

BRASIL. Resolução n ${ }^{\circ}$ 6, de 20 de setembro de 2012. Define Diretrizes Curriculares Nacionais para a Educação Profissional Técnica de Nível Médio. Diário Oficial da República Federativa do Brasil, Brasília, DF, 20 set. 2012. Disponível em: $<$ http://portal.mec.gov.br/index.php?option $=$ com_docman\&view $=$ download\&alias $=11663$ rceb006-12-pdf\&category_slug=setembro-2012-pdf\&Itemid=30192>. Acesso em: 12 dez. 2017. 


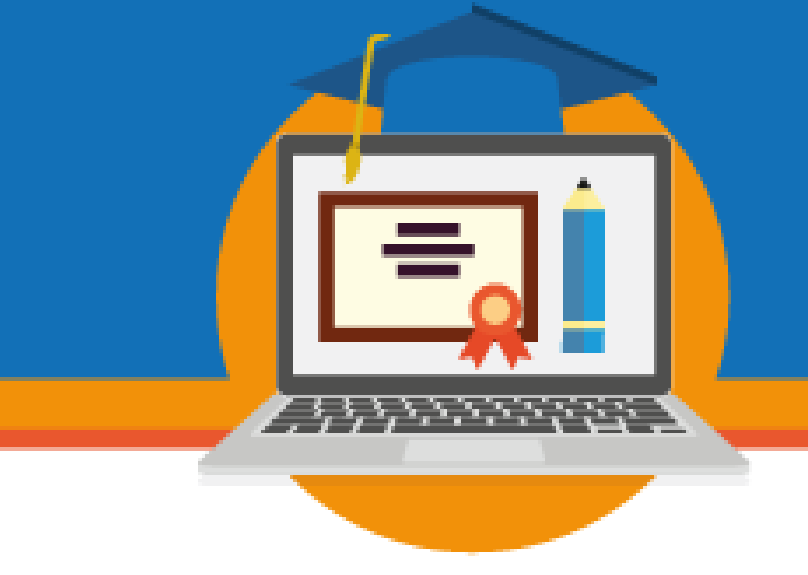

CONSUP. IFG. Resolução $n^{0}$ 33, de 02 de outubro de 2017. Aprova as Diretrizes operacionais para inclusão de carga horária na modalidade a distância em cursos presenciais do IFG. Disponível em: < https://www.ifg.edu.br/attachments/article/209/Resolu\%C3\%A7\% C3\%A3o\%20033\%202017.pdf>. Acesso em: 20 fev. 2018.

IFG. Instituto Federal de Goiás. Plano de Desenvolvimento Institucional - PDI 2012-2016. Disponível em: $<$ https://www.ifg.edu.br/attachments/article/122/pdi.pdf $>$. Acesso em: $12 \mathrm{dez}$. 2017.

MOODLE IFG. Disponível em: <http://ead.ifg.edu.br/>. Acesso em 12 dez. 2017.

PRETI, O. Educação a distância e globalização: desafios e tendências. Revista Brasileira de Estudos Pedagógicos, Brasília, v. 79, n. 191, p. 19-30, jan./abr. 1998.

SANTOS, C. A.; NOGUEIRA, D. X. P. A expansão da educação superior a distância e os novos marcos regulatórios: definições e desafios na perspectiva da qualidade. In: LIMA, D. C. B. P.; SANTOS, C. A.; TOSCHI, M. S. (Orgs.). Educação a Distância (EaD): Realidades, Evolução e Contextos. Anápolis, GO: UEG, 2017.

TOSCHI, M. S. A educação a distância no Brasil: caracterização, regulação e comercialização mundial e perspectiva de formação e de inclusão digital. In: Luiz Fernandes Dourado (Org.). Subsídios para a discussão sobre as políticas de gestão da Universidade/Educação Superior. Brasília: INEP, 2004. 